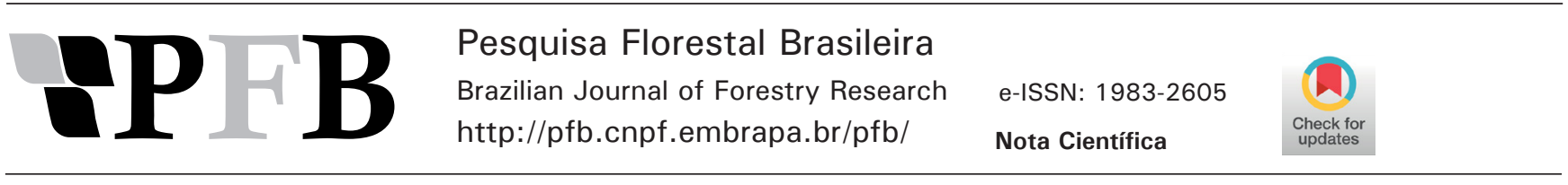

\title{
Diodos emissores de luz (LEDs) usados no cultivo in vitro de Eugenia involucrata
}

\author{
Charlene Moro Stefanel ${ }^{1}$ (D), Lia Rejane Silveira Reiniger ${ }^{1}$ (D), Leandro Dutra da Silva ${ }^{1}$ (D), Silvia Machado dos Santos Rabaiolli ${ }^{1}$ (D), \\ Karol Buuron da Silva ${ }^{1}$ (D)
}

${ }^{1}$ Universidade Federal de Santa Maria, Departamento de Fitotecnia, Avenida Roraima n 1000, Bairro Camobi, CEP 97105-900, Santa Maria, RS, Brasil

"Autor correspondente:

chastefanel@gmail.com

Termos para indexação:

Biotecnologia vegetal

Cultura de tecidos

Espécie florestal

Index terms:

Plant biotechnology

Tissue culture

Forest species

Histórico do artigo:

Recebido em 29/04/2019

Aprovado em 25/09/2020

Publicado em 31/12/2020

\section{cc) $(1) \ominus$

Eugenia involucrata De Candolle, popularmente conhecida como cerejeira-do-mato, é uma espécie frutífera nativa pertencente à família Myrtaceae, com ocorrência de Minas Gerais ao Rio Grande do Sul, podendo, ainda, ser encontrada em países vizinhos, como Argentina, Paraguai e Uruguai. A espécie possui características que a tornam ornamental e de útil aplicação em parques, jardins e na arborização de ruas (Lorenzi, 2016). Devido à alta densidade de sua madeira, pode ser utilizada para a confecção de pequenas ferramentas agrícolas, para lenha e para carvão (Carvalho, 2009; Lorenzi, 2016).

\begin{abstract}
Resumo - Esse trabalho objetivou avaliar o efeito do tipo de luz no cultivo in vitro de Eugenia involucrata. Os tratamentos consistiram do cultivo sob diodos emissores de luz (LEDs) de cor vermelho, azul, verde ou branco e lâmpadas fluorescentes. Nos cultivos sob LEDs branco e azul foram observadas as maiores médias de estabelecimento; sob o azul e lâmpadas fluorescentes, o maior número de folhas; sob o azul, o maior número de brotos; sob o branco, menor contaminação bacteriana; e sob o verde os piores resultados. LEDs azul, vermelho, branco e lâmpadas fluorescentes influenciam favoravelmente a propagação in vitro de E. involucrata.
\end{abstract}

\section{Light emitting diodes (LEDs) used in vitro culture of Eugenia involucrata}

\begin{abstract}
We aimed to evaluate the effect of light type in vitro culture of Eugenia involucrata. The treatments consisted of growing the species under light emitting diodes (LEDs) of different color spectra and fluorescent lamps. The highest average of plants establishment in the cultures under white and blue LEDs; under blue and fluorescent (he registered the largest number of leaves; under blue, the largest number of shoots and under white, less bacteria contamination. When plants were under green influence positively in vitro propagation of E. involucrata.
\end{abstract}

Apesar da potencialidade de uso da espécie, sua disseminação por via seminal é comprometida, uma vez que possui sementes recalcitrantes, as quais necessitam manter um teor de água relativamente elevado para que a sua germinação não seja prejudicada (Carvalho, 2009). Diante da limitação da sua propagação por sementes, uma das alternativas mais promissoras para a multiplicação da espécie é a utilização das técnicas de propagação vegetativa, em especial a micropropagação, que tem se destacado como uma ferramenta de grande impacto, tanto no âmbito científico quanto no econômico (Golle et al., 2013). 
Entretanto, o emprego da micropropagação pode ser limitado, devido, entre outros, ao elevado custo para a obtenção de mudas (Erig \& Schuch, 2005). É necessário que para cada espécie sejam realizados ajustes em seus protocolos (como o comprimento de onda utilizado), a fim de otimizar as condições de cultivo (Sartor et al., 2013) e reduzir custos. O comprimento de onda específico, a densidade de fluxo de fótons e o fotoperíodo utilizados, podem influenciar a morfogênese das plantas cultivadas in vitro (Lian et al., 2002). Há indícios de uma menor eficiência de multiplicação e crescimento na presença de lâmpadas fluorescentes brancas, o que pode ser decorrente do fato destas emitirem diferentes comprimentos de onda entre 350 e $750 \mathrm{~nm}$, e somente entre 400 e $700 \mathrm{~nm}$ são considerados mais importantes para a fotossíntese (Taiz \& Zeiger, 2013).

Os diodos emissores de luz (LEDs) são considerados uma opção bastante promissora, por apresentarem características importantes em relação às lâmpadas fluorescentes, que são convencionalmente usadas em laboratórios de micropropagação. Os LEDs possuem alta eficiência na geração de luz com baixa emissão de calor, podem ter sua intensidade e composição espectral controladas e, principalmente, são mais econômicos (Lazzarini et al., 2017; Rocha et al., 2017). Além disso, estudos mostraram que o uso de LEDs incrementa a taxa de multiplicação dos explantes e é capaz de proporcionar maior comprimento e número de brotações, devido à melhoria na qualidade de luz (Rocha et al., 2017).

Diante do exposto, o presente trabalho teve por objetivo avaliar o efeito do tipo de luz no cultivo in vitro de Eugenia involucrata.

O experimento foi conduzido em delineamento inteiramente casualizado em arranjo bifatorial $(5 \times 2)$, em que os níveis do fator A referem-se aos diferentes tipos de luz utilizados, e os níveis do fator B referem-se ao período de cultivo, sendo 30 ou 60 dias, totalizando 10 tratamentos. Os tratamentos consistiram do cultivo em fotoperíodo de $16 \mathrm{~h}$ sob iluminação por diferentes espectros de cor (branco, azul, verde ou vermelho) fornecidos por lâmpadas LED tipo PAR 20/C ou lâmpadas fluorescentes brancas frias tipo luz do dia com intensidade luminosa de $20 \mu \mathrm{mol} \mathrm{m} \mathrm{m}^{-2} \mathrm{~s}^{-1}$ (tratamento controle). As prateleiras que continham os tratamentos foram isoladas com papel preto, a fim de evitar a interferência de outros espectros luminosos. Os tratamentos com iluminação LED continham 6 lâmpadas cada, distantes $15 \mathrm{~cm}$ uma da outra.

A unidade experimental foi composta por 10 frascos de vidro com capacidade para $150 \mathrm{~mL}$, contendo $30 \mathrm{~mL}$ de meio nutritivo $1 / 2$ MS (Murashige \& Skoog, 1962) e dois explantes em cada frasco, totalizando 100 unidades experimentais e 200 unidades amostrais.

O meio nutritivo utilizado foi o $1 / 2 \mathrm{MS}$ composto pela diluição do meio MS à metade de sua concentração normal de sais e vitaminas, acrescido de $10 \mathrm{~g} \mathrm{~L}^{-1} \mathrm{de}$ sacarose, $50 \mathrm{mg} \mathrm{L}^{-1}$ de mio-inositol e $4 \mathrm{~g} \mathrm{~L}^{-1}$ de ágar. $\mathrm{O}$ $\mathrm{pH}$ foi ajustado para 6 , anteriormente à solidificação com ágar. Na sequência, o meio nutritivo foi autoclavado a $121^{\circ} \mathrm{C}$ e $1 \mathrm{~atm}$ de pressão durante $15 \mathrm{~min}$.

Como explantes, foram utilizados segmentos nodais oriundos de matrizes em casa de vegetação, com aproximadamente $1 \mathrm{~cm}$ de comprimento, previamente desinfestados com etanol a $70 \%(\mathrm{v} / \mathrm{v})$ durante $30 \mathrm{~s}$, hipoclorito de sódio a 2,5\% (v/v) durante $10 \mathrm{~min}$ e hipoclorito de cálcio a $2 \%(\mathrm{v} / \mathrm{v})$ por $10 \mathrm{~min}$. Em seguida, os explantes foram enxaguados três vezes com água destilada e autoclavada. Após a inoculação dos explantes em meio nutritivo, os frascos foram vedados com papel alumínio e mantidos em sala de crescimento com temperatura controlada de $25^{\circ} \mathrm{C} \pm 2$. Após 30 e 60 dias de cultivo in vitro, foram avaliadas as variáveis: estabelecimento (\%) (explantes verdes, vivos, que apresentaram qualquer aspecto de desenvolvimento), número de folhas, número de brotos (considerando-se como broto qualquer desenvolvimento das gemas do explante), contaminação bacteriana (\%) (presença de colônias bacterianas junto aos explantes) e número de gemas (considerando-se gemas adventícias, oriundas da organogênese dos tecidos e não gemas já pré-existentes, comuns em segmentos nodais).

Após testar a normalidade dos erros por meio do teste de Kolmogorov-Smirnov e a homogeneidade de variâncias pelo teste de Bartlett, as variáveis foram transformadas, sempre que necessário, pela função $\sqrt{\mathrm{x}+0,5}$, sendo $\mathrm{x}$ o valor observado. As variáveis foram submetidas à análise de variância e, quando o valor de F foi significativo, utilizou-se a comparação das médias pelo teste de Tukey ao nível de 5\% de probabilidade de erro, para tratamentos qualitativos. Foi utilizado o pacote estatístico Sisvar (Sistema para Análise de Variância) versão 5.6 (Ferreira, 2014). A precisão dos ensaios foi estimada pelo índice de variação (IV), calculado pela Equação 1 (Pimentel-Gomes, 2009). 


$$
\mathrm{IV}=\frac{\mathrm{CV}}{\sqrt{\mathrm{N}}}
$$

Em que, IV = índice de variação; $\mathrm{CV}=$ coeficiente de variação e $\mathrm{N}=$ número de repetições.

Para as variáveis estabelecimento $(\mathrm{p}=0,0142)$, número de folhas $(\mathrm{p}=0,0048)$, número de brotos $(\mathrm{p}=$ $0,0062)$ e contaminação bacteriana $(p=0,0436)$, foi observado efeito significativo somente do fator principal tipo de luz, não sendo observado efeito significativo do fator principal período de cultivo, tampouco de sua interação (Tabela 1). Entretanto, para a variável número de gemas $(p=0,0108)$, foi observado efeito significativo somente do fator principal período de cultivo in vitro.

Para a variável estabelecimento, observaram-se as maiores médias no cultivo sob os LEDs azuis ou LEDs brancos (em torno de $40 \%$ ), diferindo estatisticamente dos LEDs verdes, em cuja presença houve as menores médias (Tabela 1). No cultivo sob LEDs vermelhos e lâmpadas fluorescentes, não foram observadas médias de estabelecimento diferentes daquelas registradas com os outros LEDs (azuis, brancos ou verdes). O maior número de explantes estabelecidos nesses espectros pode ser explicado pelo fato de que a luz azul possui papel fundamental nas relações hídricas e trocas gasosas (Cosgrove, 1981) e, consequentemente, no crescimento e produção vegetal. A utilização de LED branco proporciona maior crescimento das plantas, pois permite que a luz penetre mais facilmente nas folhas para ser utilizada na fotossíntese, como foi observado em Lactuca sativa hidropônica (Lin et al., 2013), o que pode explicar os resultados obtidos com Eugenia involucrata no presente ensaio. Por outro lado, o reduzido estabelecimento observado com o emprego do LED verde pode ser explicado, de maneira geral, por esse tipo de luz promover a redução fotossintética em plantas cultivadas in vitro (Taiz \& Zeiger, 2013).

Tabela 1. Estabelecimento (\%), número de folhas, número de brotos e contaminação bacteriana (\%) em explantes de Eugenia involucrata, em função de diferentes tipos de luz, cultivados em meio nutritivo MS, com a concentração de sais reduzida à metade ( $(1 / 2 \mathrm{MS})$, independente do período de cultivo in vitro.

Table 1. Establishment (\%), number of leaves, number of shoots and bacteria contamination (\%) in explants of Eugenia involucrata, according to different types of light, grown in nutrient medium MS, with the concentration of salts reduced to half $(1 / 2 \mathrm{MS})$, regardless of the in vitro culture period.

\begin{tabular}{|c|c|c|c|c|}
\hline Tipos de luz & $\begin{array}{c}\text { Estabelecimento } \\
(\%)\end{array}$ & Número de folhas & Número de brotos & $\begin{array}{c}\text { Contaminação bacteriana } \\
(\%)\end{array}$ \\
\hline LED branco & $41,17 \mathrm{a}^{*}$ & $3,39 \mathrm{ab}^{*}$ & $1,67 \mathrm{ab}^{*}$ & $17,61 \mathrm{a}^{*}$ \\
\hline LED azul & $42,39 \mathrm{a}$ & $4,00 \mathrm{a}$ & $2,00 \mathrm{a}$ & $59,22 \mathrm{~b}$ \\
\hline LED verde & $7,33 \mathrm{~b}$ & $0,39 \mathrm{~b}$ & $0,28 \mathrm{~b}$ & $62,78 \mathrm{~b}$ \\
\hline LED vermelho & $23,83 \mathrm{ab}$ & $1,44 \mathrm{ab}$ & $0,72 \mathrm{ab}$ & $51,78 \mathrm{~b}$ \\
\hline Lâmpadas fluorescentes & $38,72 \mathrm{ab}$ & $3,89 \mathrm{a}$ & $1,05 \mathrm{ab}$ & $64,55 \mathrm{~b}$ \\
\hline Média & 30,69 & 2,62 & 1,14 & 51,19 \\
\hline IV & 7,48 & 19,19 & 14,47 & 7,47 \\
\hline
\end{tabular}

*Na coluna, médias seguidas pela mesma letra minúscula, não diferem significativamente pelo teste de Tukey $(\mathrm{p}>0,5)$. IV = índice de variação.

A maior média de número de folhas foi obtida sob os LEDs azuis e lâmpadas fluorescentes (4,00 e 3,89, respectivamente), semelhante estatisticamente a dos LEDs branco e vermelho (Tabela 1). Quando sob LEDs verdes, foi observada a menor média de emissão de folhas do experimento $(0,39)$. Para o número de brotos, as maiores médias foram obtidas no cultivo sob LEDs azuis $(2,00)$ e as menores, sob os verdes $(0,28)$.

Os resultados obtidos em relação à proliferação de folhas de Eugenia involucrata podem ser decorrentes da resposta das culturas à luz azul, que desempenha uma série de funções morfogenéticas, além de regular processos metabólicos, influenciar a produção e o crescimento vegetal, influenciar positivamente o desenvolvimento de cloroplastos e a biossíntese de moléculas de clorofila (Taiz \& Zeiger, 2013; Lazzarini et al., 2017). Igualmente, os resultados observados no presente trabalho corroboram aqueles verificados no cultivo in vitro de Platycodon grandiflorum, em que também foi obtido o maior número de folhas sob os LEDs azuis (Liu et al., 2014). 
Da mesma maneira, para o número de brotos, as maiores médias foram obtidas no cultivo sob LEDs azuis e as menores, sob os verdes. Esse comportamento desfavorável do espectro na faixa de verde pode ser justificado pelo fato desse comprimento de luz promover redução fotossintética. Entretanto, a média obtida sob os LEDs azuis é igual à média registrada em outro estudo com Eugenia involucrata, em que foram utilizados os fitorreguladores Ácido $\alpha$-Naftaleno Acético (ANA) a $0,5 \mu \mathrm{M}$ e Thidiazuron (TDZ) a $32 \mu \mathrm{M}$, em cultivo sob lâmpadas fluorescentes (Golle et al., 2017), o que é um resultado muito satisfatório, uma vez que com a utilização somente de lâmpadas LED obteve-se média igual àquela que necessitou o emprego de dois fitorreguladores (ANA e TDZ). Com isso, haveria uma significativa redução de custos para a formação de mudas da espécie, visto que não seria necessária a adição de fitorreguladores no meio nutritivo, além de que a utilização de lâmpadas LEDs na técnica da micropropagação proporciona efetiva economia de energia elétrica (Rocha et al., 2015).

O número de brotos observados nos cultivos sob LEDs brancos ou vermelhos ou lâmpadas fluorescentes não diferiram daquelas obtidos com o emprego de LEDs verdes, o que indica que, possivelmente, não são adequados para a fase de multiplicação da micropropagação de Eugenia involucrata. Contrariamente, em Saccharum officinarum L. foi identificado um elevado potencial do uso de LEDs brancos na fase de multiplicação, uma vez que promoveu o desenvolvimento de maior número de brotações por explante (Ferreira et al., 2016).

Para a variável contaminação bacteriana, observou-se a menor média sob os LEDs brancos (abaixo de 20\%), diferindo estatisticamente dos demais tipos de luz testados (Tabela 1).

A contaminação bacteriana, geralmente de origem endógena, é frequentemente observada em cultivos in vitro de Eugenia involucrata (Golle et al., 2013), porém, no presente estudo, constatou-se redução desses contaminantes quando os explantes receberam iluminação por meio de LEDs brancos. Esse resultado pode ser justificado pelo fato de que a luz branca promove incremento na fotossíntese por influenciar o balanço hormonal natural das plantas (Lin et al., 2013). Sendo assim, a qualidade da luz utilizada pode proporcionar a indução de balanços fisiológicos favoráveis a respostas específicas no crescimento das plantas (Morini \& Muleo,
2003), desfavorecendo, simultaneamente, a proliferação desses contaminantes nesse espectro de luz específico.

Obteve-se o maior número de gemas $(0,93)$ aos 30 dias, de cultivo in vitro do que aos 60 dias $(0,27)$, mas não houve efeito significativo do tipo de luz sobre essa variável (Tabela 1).

O maior número de gemas aos 30 dias em comparação aos 60 dias de cultivo in vitro, provavelmente, se deve ao seu desenvolvimento em brotos. Entretanto, estudos realizados com Eucalyptus benthamii $x$ Eucalyptus dunnii demonstraram que a utilização da luz branca convencional (fluorescente), associado a aproximadamente $0,15 \mu \mathrm{M}$ de BAP, proporcionou maior número de gemas por explantes $(20,2)$, aos 60 dias de cultivo in vitro (Brondani et al., 2009), média muito superior à registrada no presente trabalho. Esse fato pode ser explicado pela adição do fitorregulador BAP ao meio nutritivo, o qual possui eficiência no processo de multiplicação pelo desenvolvimento de gemas axilares preexistentes ou, também, indução de gemas adventícias (Taiz \& Zeiger, 2013).

\section{Conclusões}

Pode-se inferir, que o tipo de luz utilizado durante o cultivo in vitro, mais precisamente o comprimento de onda, exerce influência no número de brotações em Eugenia involucrata.

Os diodos emissores de luz (LEDs) azul, vermelho e branco, bem como as lâmpadas fluorescentes, de maneira geral, influenciam favoravelmente o desenvolvimento in vitro de Eugenia involucrata, sendo que sob LED branco há menor contaminação bacteriana.

\section{Agradecimentos}

O presente trabalho foi realizado com apoio da Coordenação de Aperfeiçoamento de Pessoal de Nível Superior - Brasil (CAPES) - Código de Financiamento 001, e do Conselho Nacional de Desenvolvimento Científico e Tecnológico (CNPq).

\section{Referências}

Brondani, G. E. et al. Estabelecimento, multiplicação e alongamento in vitro de Eucalyptus benthamii Maiden \& Cambage x Eucalyptus dunnii Maiden. Revista Árvore, v. 33, n. 1, p. 1119, 2009. https://doi.org/10.1590/S0100-67622009000100002. 
Carvalho, P. E. R. Cerejeira Eugenia involucrata. Colombo: Embrapa Florestas, 2009. (Embrapa Florestas. Comunicado técnico, 224). https://www.infoteca.cnptia.embrapa.br/infoteca/handle/ doc/578655.

Cosgrove, D. J. Rapid suppression of growth by blue light occurrence, time course, and general characteristics. Plant Physiology, v. 67, n. 3, p. 584-590, 1981.

Erig, A. C. \& Schuch, M. W. Micropropagação fotoautotrófica e uso da luz natural. Ciência Rural, v. 35, n. 4, p. 961-965, 2005. https:// doi.org/10.1590/S0103-84782005000400039.

Ferreira, D. F. Sisvar: a Guide for its Bootstrap procedures in multiple comparisons. Ciência eAgrotecnologia, v. 38, n. 2, p. 109-112, 2014. https://doi.org/10.1590/S1413-70542014000200001.

Ferreira, L. T. et al. Fonte de luz e concentração de sacarose no cultivo in vitro da cana de-açúcar (RB 867515). Plant Cell Culture \& Micropropagation, v. 12, n. 2, p. 46-52, 2016. http://177.105.2.193/ ojs/index.php/PlantCellCultureMicropropagation/article/view/93 .

Golle, D. P. et al. Combination of NAA and TDZ for in vitro multiplication of Eugenia involucrata DC. Revista Árvore, v. 41, n. 5, e410509, 2017. https://doi.org/10.1590/1806-90882017000500009.

Golle, D. P. et al. Estabelecimento e desenvolvimento in vitro de Eugenia involucrata DC.: influência do tipo de explante e do meio nutritivo. Ciência Florestal, v. 22, n. 1, p. 207-214, 2013. https:// doi.org/10.5902/198050985092.

Lazzarini, L. E. S. et al. Uso de diodos emissores de luz (LED) na fisiologia de plantas cultivadas: revisão. Scientia Agraria Paranaensis, v. 16, n. 2, p. 137-144, 2017. https://doi. org/10.18188/1983-1471/sap.v16n1p137-144.

Lian, M. L. et al. Effects of light emitting diodes (LEDs) on the in vitro induction and growth of bulblets of Lilium oriental hybrid 'Pesaro'. Scientia Horticulturae, v. 94, n. 3-4, p. 365-370, 2002. https://doi.org/10.1016/S0304-4238(01)00385-5.

Lin, K. H. et al. The effects of red, blue, and white light-emitting diodes on the growth, development, and edible quality of hydroponically grown lettuce (Lactuca sativa L. var. capitata). Scientia Horticulturae, v. 150, n. 1, p. 86-91, 2013. https://doi. org/10.1016/j.scienta.2012.10.002.
Liu, M. et al. Evaluation of leaf morphology, structure and biochemical substanceof balloon flower (Platycodon grandiflorum (Jacq.) A. DC.) plantlets in vitro under different light spectra. Scientia Horticulturae, v. 174, n. 1, p. 112-118, 2014. https://doi. org/10.1016/j.scienta.2014.05.006.

Lorenzi, H. (Ed). Árvores brasileiras: manual de identificação e cultivo de plantas arbóreas nativas do Brasil. 7 ed. Nova Odessa: Instituto Plantarum, 2016. 384 p.

Morini, S. \& Muleo, R. Effects of light quality on micropropagation of woody species. In: Jain, S. M. \& Ishi, K. (Ed.). Micropropagation of woody trees and fruits. Dordrecht: Klwe Academic, 2003. p. 3-35.

Murashige, T. \& Skoog F. A revised medium for rapid growth and bio assays with tobacco tissue cultures. Physiologia Plantarum, v. 15, p. 473-497, 1962. https://doi.org/10.1111/j.1399-3054.1962.tb08052.x.

Pimentel-Gomes, F. (Ed.). Curso de estatística experimental. 15 ed. Piracicaba: FEALQ, 2009. 451 p.

Rocha, P. S. G. et al. New light sources for in vitro potato micropropagation. Bioscience Journal, v. 31, n. 5, p. 1312-1318, 2015.

Rocha, P. S. G. et al. Uso de LEDs na multiplicação in vitro de três cultivares de bananeira. Revista Colombiana de Ciências Hortícolas, v. 11, n. 2, p. 247-252, 2017. https://doi.org/10.17584/ rcch.2017v11i2.6666.

Sartor, F. R. et al. Diferentes meios de cultura e antioxidantes no estabelecimento in vitro do Jacarandá da Bahia. Bioscience Journal, v. 29, n. 2, p. 408-411, 2013. http://www.seer.ufu.br/index.php/ biosciencejournal/article/view/14109/12283.

Taiz, L. \& Zeiger, E. (Ed.). Fisiologia vegetal. 5 ed. Porto Alegre: Artemed, 2013. 820 p. 